Article

\title{
A Point-of-Care Device for Molecular Diagnosis Based on CMOS SPAD Detectors with Integrated Microfluidics
}

\author{
Joan Canals*(D), Nil Franch (D), Oscar Alonso (D), Anna Vilà $\mathbb{D}^{D}$ and Angel Diéguez \\ Electronic and Biomedical Engineering Department, University of Barcelona, 08028 Barcelona, Spain; \\ nfranch@el.ub.edu (N.F.); oalonso@el.ub.edu (O.A.); avila@el.ub.edu (A.V.); adieguez@el.ub.edu (A.D.) \\ * Correspondence: jcanals@el.ub.edu; Tel.: +34-93-403-9146
}

Received: 3 December 2018; Accepted: 17 January 2019; Published: 22 January 2019

\begin{abstract}
We describe the integration of techniques and technologies to develop a Point-of-Care for molecular diagnosis PoC-MD, based on a fluorescence lifetime measurement. Our PoC-MD is a low-cost, simple, fast, and easy-to-use general-purpose platform, aimed at carrying out fast diagnostics test through label detection of a variety of biomarkers. It is based on a 1-D array of 10 ultra-sensitive Single-Photon Avalanche Diode (SPAD) detectors made in a $0.18 \mu \mathrm{m}$ High-Voltage Complementary Metal Oxide Semiconductor (HV-CMOS) technology. A custom microfluidic polydimethylsiloxane cartridge to insert the sample is straightforwardly positioned on top of the SPAD array without any alignment procedure with the SPAD array. Moreover, the proximity between the sample and the gate-operated SPAD sensor makes unnecessary any lens or optical filters to detect the fluorescence for long lifetime fluorescent dyes, such as quantum dots. Additionally, the use of a low-cost laser diode as pulsed excitation source and a Field-Programmable Gate Array (FPGA) to implement the control and processing electronics, makes the device flexible and easy to adapt to the target label molecule by only changing the laser diode. Using this device, reliable and sensitive real-time proof-of-concept fluorescence lifetime measurement of quantum dot $\operatorname{Qdot}^{\mathrm{TM}} 605$ streptavidin conjugate is demonstrated.
\end{abstract}

Keywords: fluorescence lifetime; low-cost; molecular diagnosis; microfluidics; point-of-care; CMOS; single-photon avalanche diode; laser diode

\section{Introduction}

Nowadays, fluorescence-based techniques have become among the most widely used methods in clinical analysis and biomedical diagnosis [1] and have been applied in the field of high-throughput biotechnology for Fluorescence Activated Cell Sorting (FACS) and High-Throughput Screening (HTS) thanks to their accuracy, sensitivity (single molecule detection), and targeted labelling of biological samples [2].

In particular, fluorescence measurements can provide information not only on the specific molecular makeup of a sample, but also on the local environment surrounding the fluorescence molecule or fluorophore (such as $\mathrm{pH}$, ion concentrations, etc.), which give value to the fluorescence based techniques a powerful analysis tool [3-6]. However, the fluorescence techniques based on intensity measurements are prone to misinterpretation due to their dependence on parameters such as excitation light intensity and fluorophore concentration. In contrast, time-resolved fluorescence techniques can address the limitations of intensity-based measurements by time resolving the fluorescence decay or lifetime, which is an intrinsic molecular property, thus independent of the fluorophore concentration and the excitation intensity [7]. Moreover, the fluorescence lifetime improves 
the specificity of the fluorescence measurement by time domain discrimination. This allows for the differentiation of fluorophores with overlapping emission spectra but different lifetimes [8], as well as to discern the light of interest from the background light due to autofluorescence of the biological sample, which can distort quantitative intensity based measurements [9].

Thus, many efforts have been done in recent years to develop time-resolved methods as Time Resolved Fluorescence Spectroscopy (TRFS) and Fluorescence Lifetime IMaging (FLIM), which allow in vivo characterization and diagnosis of biological samples [10-15]. However, conventional equipment needed to perform fluorescence lifetime measurements-a pulsed laser; a complex opto-mechanical system with lens and filters, generally a microscope; and a photon transducer such as a CCD camera or photomultiplier tube $[16,17]$ - is bulky and expensive, and this relegates it to research laboratories.

On the contrary, Point-of-Care $(\mathrm{PoC})$ applications, are aimed at performing analytical or diagnostic tests near the site of interest, such as a patient in a hospital or even on the field, in order to provide on-site results to the operator [18]. In the last decade, noticeable progress has been made towards the miniaturization of fluorescence-based instruments, in an effort to reduce both cost and size. Considerable gains have been achieved thanks to the integration of microfluidics [19-22] and sensing microtechnologies like Complementary Metal-Oxide-Semiconductor Single-Photon Avalanche Diodes (CMOS SPADs) [23-26], but the obtained prototypes either require bulky optical setups with filters, lens, or optical fibers to guide the light $[2,16,17,25,27-30]$ or suffer loss of sensitivity [26] or increased measurement time [8]. Very compact analysis systems have been reported [31-33], but they still require a filter to subtract the excitation light source and an expensive Time Correlated Single Photon Counting (TCSPC) card to build the histogram of the decay time.

In this work, we describe a compact general-purpose portable device, aiming to overcome the limitations of current PoC molecular diagnosis systems. In order to obtain a sensitivity comparable to actual optical instruments while a diagnosis time of a few seconds, different microtechnologies have been combined. In particular, the system integrates an array of ultra-sensitive HV-CMOS SPAD detectors with a custom interchangeable polydimethylsiloxane (PDMS) microfluidic cartridge to insert the sample, and a low-cost pulsed UV laser diode as excitation light source (Figure 1). The proximity between the sample in the microfluidic cartridge and the SPAD sensor together with the gated operation mode of the sensor [34] makes unnecessary the use of lenses and optical filters for long lifetime fluorophores, such as quantum dots (QD). Moreover, the SPAD array sensor chip is packaged using a custom developed SU-8 encapsulation able to protect the wire bonds of the chip, while at the same time acting as physical barrier for the microfluidic cartridge. The combination of the sensor packaging with the custom microfluidic chip allows placing the sample at less than $200 \mu \mathrm{m}$ from the sensor chip surface without requiring any alignment procedure. The control and processing electronics are synthetized on a FPGA, where the TCSPC technique [35] is implemented to measure the decay profile of the fluorescence with sub-nanosecond resolution. The time histogram build within the FPGA can then be read via a USB interface or directly plotted on a display. The use of a FPGA and a laser diode makes the system configurable in such a way that it can be easily adapted to the target label molecule and measurement needs.

The following sections introduces the measuring technique adopted, followed by a description of the device, and finally, a complete characterization of the device, as well as fluorescence lifetime measurements of several concentrations of quantum dot, Qdot ${ }^{\mathrm{TM}} 605$ Streptavidin Conjugate (QD605) from Thermo Fisher Scientific (Waltham, MA, USA), are reported. 


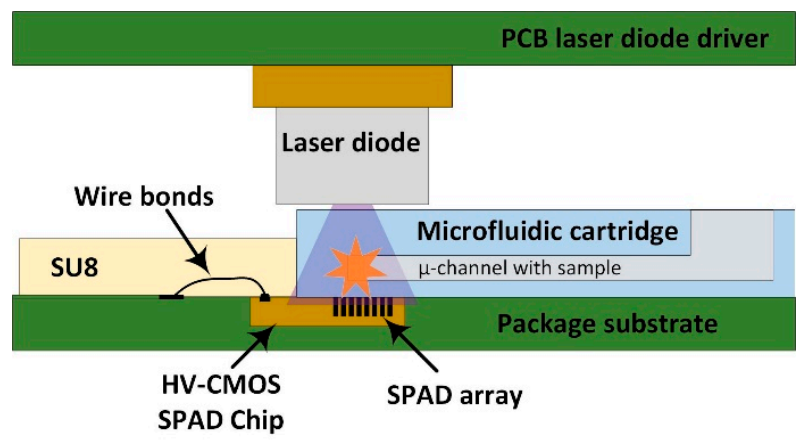

Figure 1. Cross-sectional sketch of the stack up of the system. The sample is introduced in one of the microchannels of the microfluidic cartridge, which is directly positioned on top of the SPAD array, where the wire bonds encapsulation with SU-8 prevents it from entering further.

\section{Materials and Methods}

\subsection{Materials}

In Table 1 the commercially available elements used to construct and test the PoC-MD are listed. The SPAD array chip is included. It was custom designed and fabricated with a multi-project wafer in a $0.18 \mathrm{HV}-\mathrm{CMOS}$ process. The basic electronic components are not listed for simplicity. The initial investment is high due to the raw materials such as SU8, PDMS, CW2400, and the FPGA development board. Nevertheless, the final cost of the prototype is approximately $960 €$, which is much more affordable than commercial bulky equipment.

Table 1. The basic components needed to construct the PoC-MD. It is assumed that the computer, 3D printer, and the facilities to perform soft-lithography and wire bonds are available. The costs for raw materials are divided by the estimated number of devices that can be manufactured with them.

\begin{tabular}{|c|c|c|c|}
\hline Components & Approx. Cost & Cost Per Device & Notes \\
\hline SPAD sensor chip (40 dies fabricated in a multi-project wafer) & $7000 €$ & $175 €$ & \\
\hline Zedboard Zynq-7000 Development Board from Digilent & $422 €$ & $422 €$ & \\
\hline $3 \mathrm{D}$ printed spacer (based on the 3D printer cartridge cost $(15 €)$ ) & $0.15 €$ & $0.15 €$ & \\
\hline Daughter card (includes all electronic parts and components) & $110 €$ & $110 €$ & \\
\hline \multicolumn{4}{|l|}{ Sensor Packaging } \\
\hline Substrate based on a printed circuit board & $66 €$ & $66 €$ & \\
\hline Conductive epoxy CW2400 from Chemtronics Circuit Works & $100 €$ & $2 €$ & \\
\hline $\begin{array}{l}\text { SU-8 } 100 \text { negative tone near UV photoresist from Microchem } \\
\text { Corporation }\end{array}$ & $860 €$ & $8.6 €$ & 1 \\
\hline \multicolumn{4}{|l|}{ Laser driver circuit components } \\
\hline $\begin{array}{l}\text { Laser driver circuit DC supply for } \mathrm{V}+\text { (includes all electronics } \\
\text { parts and components) }\end{array}$ & $96 €$ & $96 €$ & \\
\hline $\begin{array}{l}\text { Laser diode } 405 \mathrm{~nm} \text { and } 150 \mathrm{~mW} \text { L405P150 from Thorlabs } \\
\text { Microfluidics materials }\end{array}$ & $83 €$ & $83 €$ & \\
\hline Polydimethylsiloxane-PDMS, Dow Corning Sylgard 184 kits & $170 €$ & $3.4 €$ & 2 \\
\hline Glass coverslip 12460 S from Thermo Fisher Scientific (1000 units) & $55 €$ & $0.055 €$ & \\
\hline \multicolumn{4}{|l|}{ Fluorophore label } \\
\hline $\begin{array}{l}\text { Q10103MP } 50 \mu \mathrm{L} 1 \mu \mathrm{M} \text { QdotTM } 605 \text { Streptavidin Conjugate from } \\
\text { Thermo Fisher Scientific }\end{array}$ & $203 €$ & & \\
\hline PBS PH7.4 W/O CAMG USA PLASTIC 500 mL & $12 €$ & & \\
\hline
\end{tabular}

1. Around $5 \mathrm{~mL}$ are used to encapsulate one SPAD sensor. 2. Around 50 devices can be manufactured with $1.1 \mathrm{~kg}$ of PDMS.

PDMS was selected to manufacture the microfluidics cartridge because it has good optical properties in the range of NUV-VIS-NIR (400-1000 nm) and presents a low autofluorescence emission, which is invariant to illumination [36]. As a substrate, a glass cover slip of $150 \mu \mathrm{m}(12460 \mathrm{~S}$ from 
Thermo Fisher Scientific, Waltham, MA, USA) is selected to guarantee good transmission of the light emitted by the QD to the detector.

\subsection{Measuring Technique}

TCSPC is illustrated in Figure 2. The sample is repetitively excited by the pulsed light source. After each excitation pulse, fluorescence emission occurs and only a single photon of the many emitted can be detected by the SPAD, which remains inhibited after the detection. The arrival time of this photons is measured and follows the probability distribution of the fluorophore emission, which is then reconstructed in the histogram generated over multiple excitation/emission cycles. On the other hand, the SPAD sensor is only activated during a programmable time (the observation window, OW) that by a user-defined time with a resolution of 68 ps. The time offset between the laser pulse and the OW allows to suppress the excitation light as well as unwanted background signals (like auto-fluorescence from cells or media) from the OW without using the optical filters typical of fluorescence measurement setups [37].

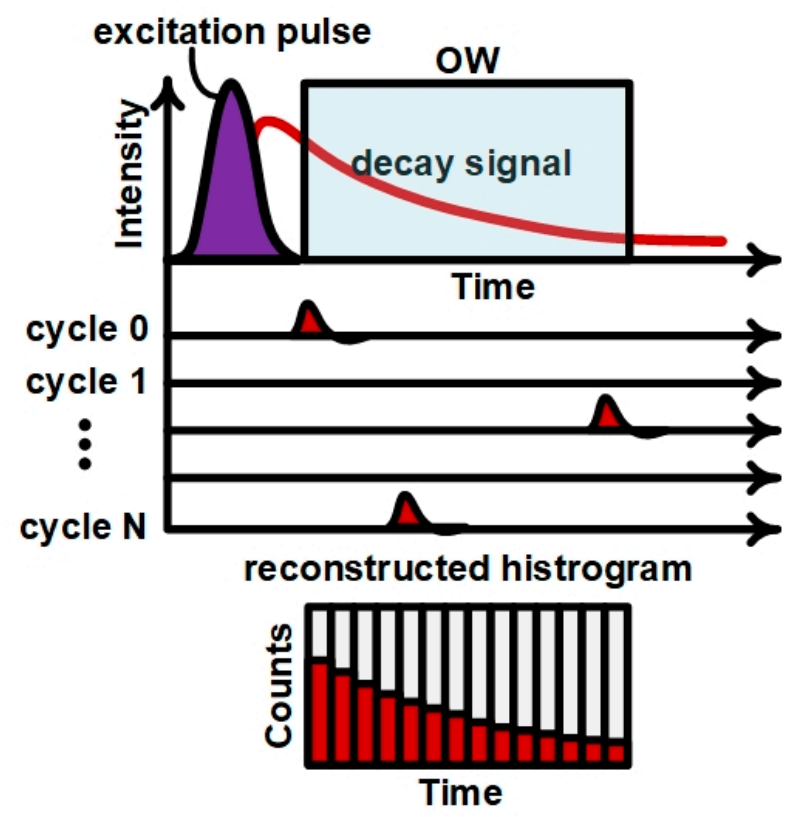

Figure 2. Measurement procedure applying the time gating to cut off the laser.

The measurement begins by setting the OW, which is delayed with respect to the laser trigger, thus preventing the excitation light from saturating the SPAD sensor. If an avalanche occurs during the OW, the time at which this event occurred is captured by the Time-to-Digital Converter (TDC) of the system controller and it is stored in the histogram memory. The TDC has a timing resolution of 68 ps with a measurement range up to $420 \mathrm{~ns}$, and the time values are quantized in bins, corresponding to respective memory positions. In order to have a significant statistical population of measurements, the measurement repeated a configurable number of times. Next, a histogram of events per time bin is built to show the decay profile. For a single fluorophore, as a first approximation, the histogram appears as an exponential decay with lifetime $\tau$ [38],

$$
I(t)=I_{0} e^{-t / \tau}
$$

The PoC-MD allows the generation of a Dark Count Rate (DCR) profile of the sensor array in a dark environment by masking the laser trigger, useful to select the SPAD-microchannel pair with the best Signal-to-Noise Ratio (SNR). The noise measurement is done like a lifetime measurement but 
without pulsing the laser diode. Once the histogram of the dark count noise is generated, the DCR is calculated as follows:

$$
\operatorname{DCR}(\mathrm{Hz})=\frac{\text { Number of counts }}{\text { Number of Measurements } \times \text { Time of } \mathrm{OW}}
$$

In the same way, the system can perform measurements of fluorescence intensity by adding the counts of the observation window while pulsing the laser.

\subsection{Device Implementation}

\subsubsection{SPAD Sensor Chip Design}

The sensor geometry (SPAD array size, array configuration, array-contact pad layout, and SPAD size) was designed together with its packaging and the microfluidics cartridge as a whole, in order to allow the straightforward stacking of the microfluidic cartridge and the die without any alignment procedure. As seen in Reference [32], the light resulting from the fluorescence in one microchannel arrives to more than one pixel, making unnecessary the use of a 2-D array. Consequently, a 1-D array gave enough information, which simplifies the readout and control electronics and reduces the number of connections and the power consumption.

The SPAD sensor array chip is implemented in a standard $0.18 \mu \mathrm{m}$ HV-CMOS process. The $3.6 \mathrm{~mm}$ $\times 1.4 \mathrm{~mm}$ chip (Figure 3), contains a 1-D array of 10 SPAD detectors with $50 \mu \mathrm{m}$ pitch (highlighted in red in the figure), along with other test structures. The active area of each detector is $8 \mu \mathrm{m}$ in diameter. Each SPAD pixel has its digital output but the control signals and the bias voltage are common to all the SPADs. All the connections of the circuit are placed on the long side of the chip and the 1-D SPAD array is placed perpendicular to them, with the first SPAD at $500 \mu \mathrm{m}$ from the edge of the bonding pads. This configuration allows a simple microfluidic design with good tolerances for its manufacture, as well as for the packaging of the sensor itself.

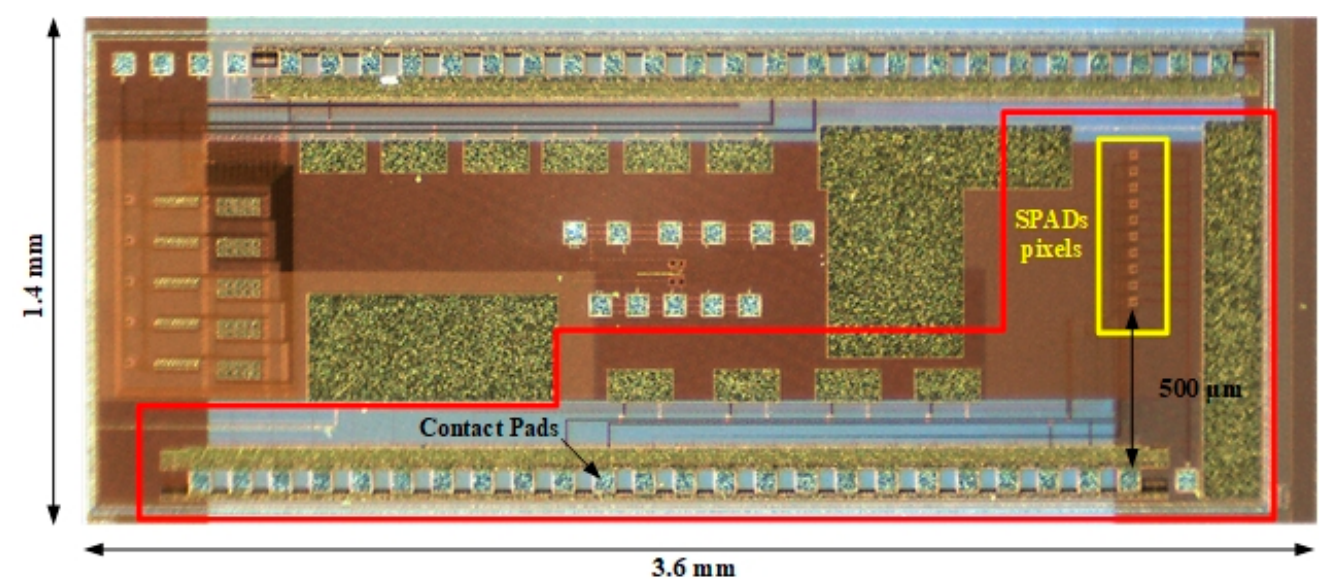

Figure 3. Photography of the ASIC with the implemented circuit highlighted in red and the 10 SPADs pixels highlighted in yellow. The first SPAD pixel is situated at $500 \mu \mathrm{m}$ from the edge of the contact pads.

The active area of the pixels is kept low to have a low dark count noise, which is proportional to the active area and the temperature [39]. The only reason to use SPADs with larger active area would be to easily align them, but this is solved by the use of 1-D array and the sensor packaging, which ensures that at least one SPAD is covered by a microfluidic channel of $100 \mu \mathrm{m}$ width.

The SPADs design is based on the work by Reference [40], but with a different readout electronics (Figure 4$)$. The $\mathrm{n}+$ cathodes are biased at a positive high voltage $\left(\mathrm{V}_{\mathrm{HV}}\right)$ beyond its breakdown voltage $\left(\mathrm{V}_{\mathrm{BD}}\right.$, approximately $\left.11.7 \mathrm{~V}\right)$ by an overvoltage $\left(\mathrm{V}_{\mathrm{OV}}\right)$ to operate in Geiger mode, $\mathrm{V}_{\mathrm{HV}}=\mathrm{V}_{\mathrm{BD}}+\mathrm{V}_{\mathrm{OV}}$. The avalanches are sensed at the $\mathrm{p}+$ anode due to its lower intrinsic capacitance to ground, which is 
beneficial in reducing the timing response, as well as the afterpulsing probability [41]. The SPADs are operated in gated mode to partially eliminate the after-pulsing and reduce the probability to detect dark counts instead of desired events [42]. Gated operation is accomplished by three external signals RST, INH and INHCNT: INHCNT inhibits the readout electronics, INH inhibits the SPAD sensor by setting the bias voltage below its breakdown voltage, and finally the RST discharges the sensing node and prepares it to measure again. Figure 4 shows the time diagram of the SPADs control signals. The pulse width of INHCNT signal determines the observation window of the SPAD. The duration of INH at low level determines the off time, which should be held relatively large to avoid the afterpulsing. Nevertheless, these sensors show almost negligible after-pulsing $(<0.2 \%)$, which is in line with other works [43] and can be avoided almost completely with a $200 \mathrm{~ns}$ of off time. The timing jitter for these sensors is expected to be below 80 ps for $1.4 \mathrm{~V}$ of overvoltage and $8 \mu \mathrm{m}$ SPAD size, accordingly with similar SPADs [43].

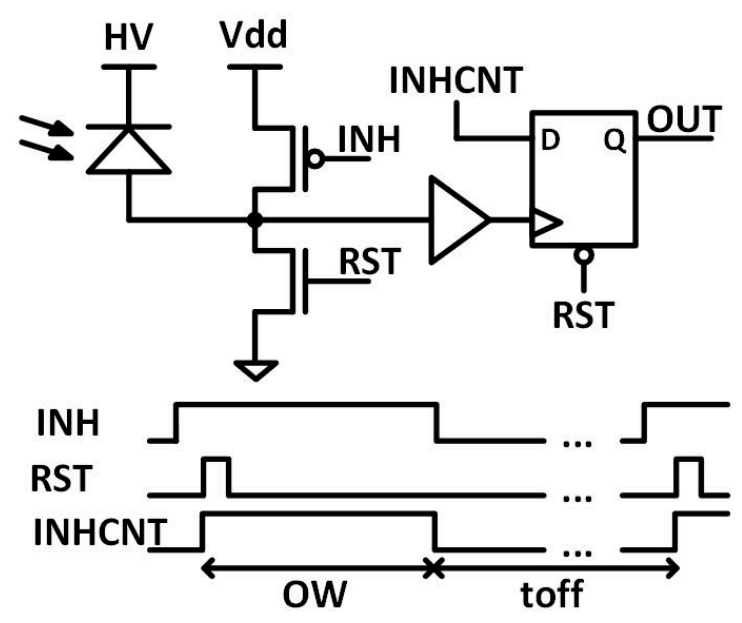

Figure 4. SPAD pixel schematic and time diagram of SPAD control signals.

\subsubsection{Sensor Packaging}

The SPAD array sensor chip is mounted on a specific Printed Circuit Board (PCB) that acts as a package substrate thanks to a recess into which the chip can be inserted. The recess is $50 \mu \mathrm{m}$ deeper than the chip height (approximately $350 \mu \mathrm{m}$ ) so that when the chip is glued with a conductive epoxy (CW2400 from Chemtronics Circuit Works) into the recess, its surface is flush with the PCB, creating a planar surface for the microfluidics. The combined PCB and chip are subjected to a dehydration bake at $150{ }^{\circ} \mathrm{C}$ for $15 \mathrm{~min}$ and wire bonded, keeping the wire bonds as flat as possible, in order to ensure a good coating.

SU-8 and photolithography are then used to encapsulate the wire bonds, and created bulge will be used as a physical limit to place the microfluidic chip (see Figure 5). SU-8 is spin coated onto the board at $1000 \mathrm{rpm}$ for $30 \mathrm{~s}$, using a process based on the recommended conditions in the SU-8 datasheet [44]. The soft-bake is performed using temperature ramping from room temperature to $65^{\circ} \mathrm{C}$ and holding for $30 \mathrm{~min}$, increasing to $95^{\circ} \mathrm{C}$ and maintaining for $90 \mathrm{~min}$ and slowly cooling down to $40^{\circ} \mathrm{C}$ before exposure. The same scheme is followed for the post-exposures bake but changing the times to 10 and $30 \mathrm{~min}$, respectively. These heating by temperature ramping and slowly cooling down, reduce the stress and any adhesion problems caused by the different thermal expansion rates of the SU8, PCB, and chip [45]. The final SU8 cap (Figure 5a) covers a surface of $4.6 \mathrm{~mm} \times 12 \mathrm{~mm}$ and extends $200 \mu \mathrm{m}$ over the chip from the edge of the pads, leaving a margin of $300 \mu \mathrm{m}$ to locate microfluidic cartridge. The resultant encapsulation is a $450 \mu \mathrm{m}$ tick, which is enough to act as for the microfluidic chip (Figure $5 \mathrm{~b}$ ). 


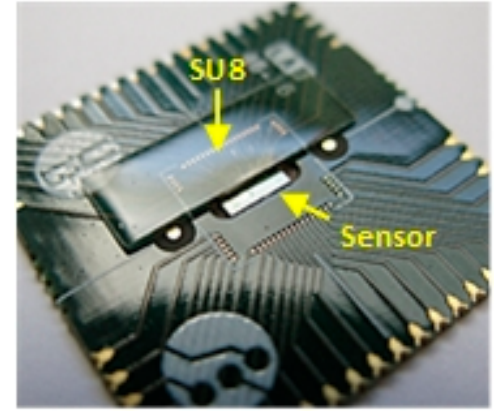

(a)

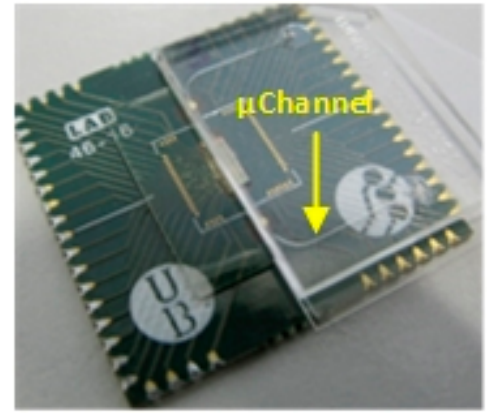

(b)

Figure 5. (a) Fully encapsulated SPAD Sensor Array chip using SU8 to protect the wire bonds; (b) SU8 wire bonds protection as stop for the microfluidic chip.

\subsubsection{Microfluidic Cartridge Fabrication}

The microfluidic cartridge was fabricated in a standard PDMS soft-lithography process $[46,47]$ using a SU-8 mold fabricated by photolithography [48,49]. The cartridge structure was obtained by mixing the base and curing agent together at a 10:1 ratio (w/w), degassing, pouring into a Petri dish with the microchannel mold therein, degassing again and curing. The resultant PDMS was cut and sealed irreversibly with a glass coverslip (12460S from Thermo Fisher Scientific) of $150 \mu \mathrm{m}$ thickness and $24 \mathrm{~mm} \times 60 \mathrm{~mm}$ shape, by exposing both sides to be bonded to an air plasma treatment at $30 \mathrm{~W}$ for $60 \mathrm{~s}$.

The structure and geometry of the microfluidic cartridge was fixed by the geometry of the SPAD sensor chip, its packaging and the selected substrate to seal the microfluidics. Figure 6a shows the design of the microfluidic chip, which consists of a single channel $100 \mu \mathrm{m}$ wide and $100 \mu \mathrm{m}$ high together with a cutting guide $(150 \mu \mathrm{m}$ wide) sited $300 \mu \mathrm{m}$ away from the microchannel to ensure its position over the SPAD sensor array within the tolerance margins (Figure 6b). Being spaced by $42 \mu \mathrm{m}$, this microchannel width guarantees that at least one sensor is fully covered by the channel (Figure 6c).

(a)
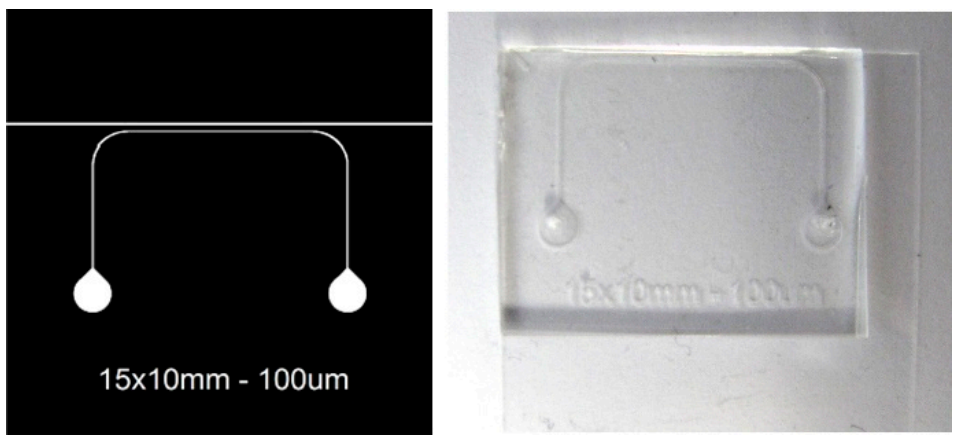

(b)
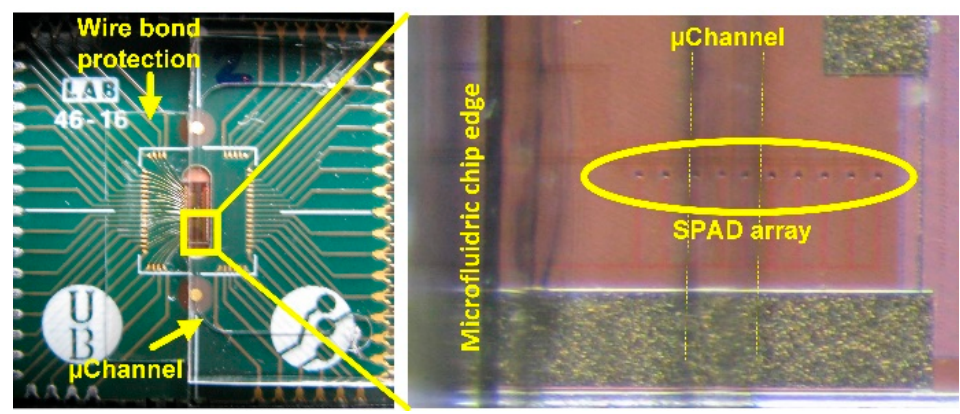

Figure 6. (a) Microfluidic design and final cartridge; (b) Microfluidic cartridge over the encapsulated chip with a detail of the microchannel over the SPAD array. 
A thickness of $2 \mathrm{~mm}$ of PDMS is sufficient to firmly connect the inlet and outlet tubes while allowing the excitation light source close enough to the sample, to prevent the need of focusing optics. The thickness of the PDMS slice is controlled by the volume of PDMS poured on the mold using a syringe, which produces a variation of $\pm 200 \mu \mathrm{m}$. The coverslip substrate allows placing the sample close enough to the SPADs $(\sim 200 \mu \mathrm{m})$ to have a good detection and provides good cartridge handling.

\subsubsection{Excitation Source}

In order to obviate the use of optical filters, a light source fast enough to be switched off, before the detector is gated on is unavoidable. While it has been reported that low-cost LEDs can be pulsed to measure the fluorescence decay times $[15,26,50]$, a more powerful light source might increase the intensity of the fluorescence signal at low concentrations and compensate the signal loss during the elapsed time between the excitation light pulse and the beginning of the observation window.

In our application, the sample excitation is achieved using a L405P150 laser diode from Thorlabs, a $405 \mathrm{~nm}$ diode with an output power of $150 \mathrm{~mW}$. The excitation wavelength was chosen to be $405 \mathrm{~nm}$ since this provides a close match with the excitation wavelength of many commonly used fluorophores including the QD605. Figure 7 shows the driving circuit used to generate sharp short pulses in order to measure short lifetimes. This circuit is based on the avalanche breakdown pulse operation of the 2N2369 small signal NPN transistor [51-54], which exhibits avalanching with performance similar to transistors dedicated to avalanche at a lower price [15]. The amplitude and width of the generated electrical pulses can be tuned by $\mathrm{V}+$ and $\mathrm{C} 1$ capacitor. The implemented circuit emits short electrical pulses of $1.6 \mathrm{~ns}$ FWHM with $10 \mathrm{~V}$ amplitude into a load of $50 \Omega$ with a repetition rate of $10 \mathrm{kHz}$, which is enough to drive the laser diode and generate sharp light pulses to stimulate the emission of the sample.

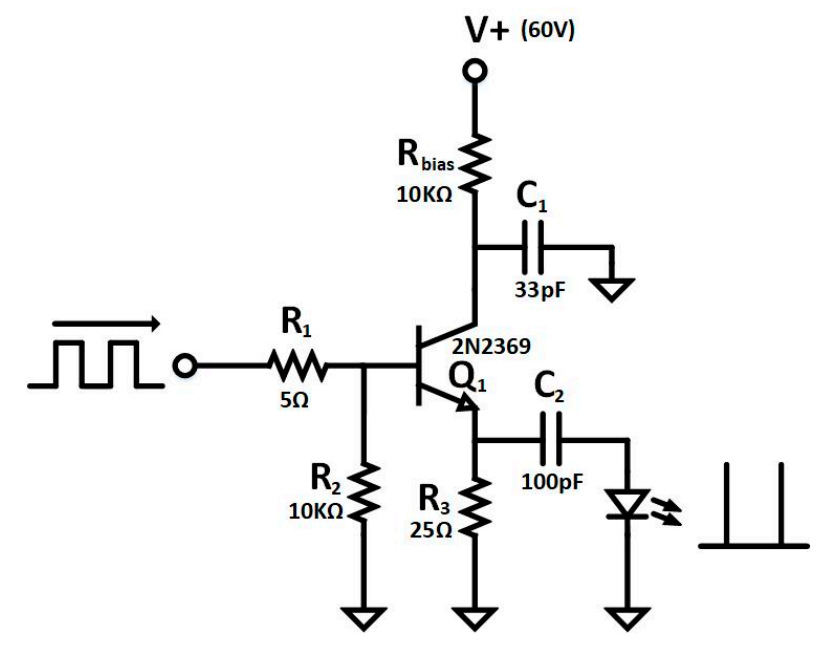

Figure 7. Simplified schematic of avalanche pulse generator.

\subsubsection{System Controller}

The system controller is based on a previous work [55], now combined with the SPAD array described in this paper, and implemented using the Zynq7020 All Programmable System-On-Chip (AP SoC) from Xilinx. While the controller can be integrated in the same chip as the SPADs [32,56-59], usually an external processor or FPGA is still required, whether for post processing the data, configuring the device, or for showing the results via PC or display. The use of Zynq 7020 AP SoC is preferable even with the increased cost that it supposes, because it introduces great flexibility brought by connecting directly a software platform with an FPGA. This solution enables the construction of an independent system with a high flexibility by reprogramming the hardware or software. 
The AP SoC consists of a processing system (PS) based on a dual-core Cortex-A9 ARM processor, and a programmable logic (PL) Artix-7 FPGA. The PS is in charge of post processing data and managing the communication with a $\mathrm{PC}$, by receiving the experiment configuration parameters and sending the resulting histogram. The PL implements the measurement technique described in Section 2.2.

\subsubsection{System Configuration}

A dedicated PCB daughter card has been designed to hold the system stack, which consists of a sandwich structure including the SPAD sensor chip, a microfluidic cartridge and an UV laser diode (Figure 8). The packaged SPAD sensor chip is situated on top of the daughter card. The laser diode and its driver are implemented on an auxiliary PCB, connected to the daughter card, and placed over the SPAD sensor chip facing the laser diode against the sensor array. The minimum distance between the laser diode and the SPADs detectors is determined by the microfluidic cartridge height $(2 \mathrm{~mm})$. A plastic spacer is designed to house the stacked system, setting the distance between the laser diode and the SPAD array at $3 \mathrm{~mm}$. An opening on one side of the spacer the custom microfluidic cartridge to be inserted and guided over the SPAD array until it reaches the SU8 stop of the sensor packaging which ensures its correct position.

The Zynq7020 AP SoC system controller is mounted on a Zedboard development board connected to the daughter card via FMC connector. This electrical connection includes all the digital signals as well as the power and ground supplies, except the high-voltages bias required by the SPADs sensors and laser diver, which are generated from the 3.3 V supply of the Zedboard by a power stage implemented on the daughter card. The Zedboard receives the measurement configuration parameters, and at the end of the measurement sends the generated histogram to a PC via USB for visualization and lifetime extraction. Figure 8 shows the complete PoC-MD configuration and the designed daughter card with the system stack-up.

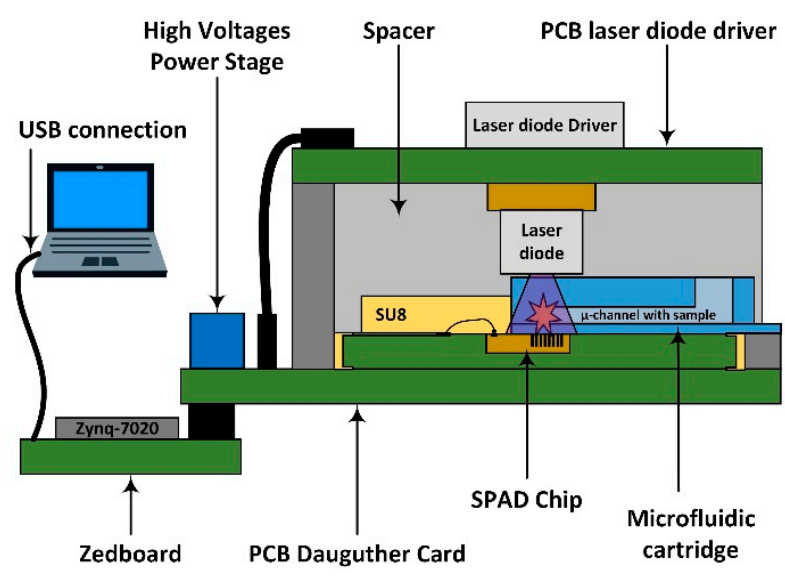

(a)

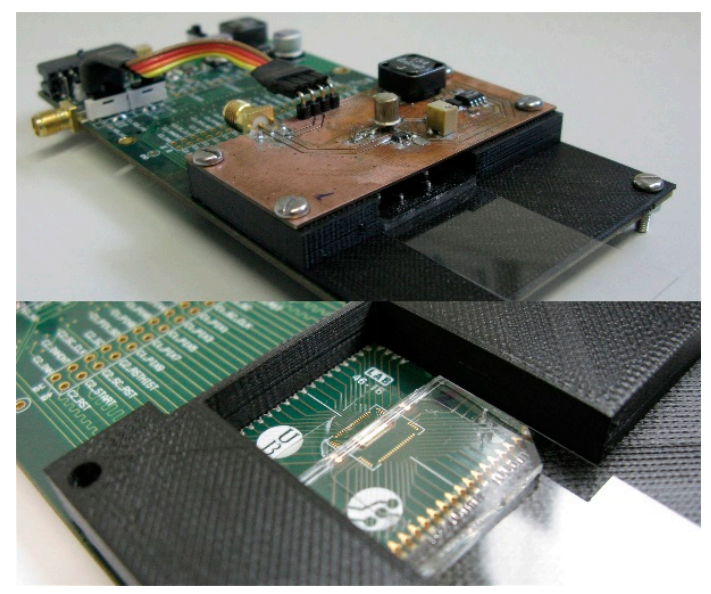

(b)

Figure 8. (a) Scheme diagram of the complete PoC-MD system with the detailed system stack; and (b) complete PCB daughter card with a detail of microfluidic cartridge guide over the SPADs sensor.

\section{Results}

\subsection{Sensor Characterization}

The device performance is determined by the main parameters characterizing individual SPADs, i.e., noise through Dark Count Rate (DCR) and sensitivity through Photon Detection Probability (PDP) [60]. DCR is measured as the rate of random pulses due to thermally generated carriers. It has a high variance due to its dependence on the number of traps in the diode. 
DCR was measured on 13 sensor chips, to take into account its variability over different SPADs. Figure 9 shows the cumulative plot of the DCR at $1.4 \mathrm{~V}$ of overvoltage at room temperature. Almost $70 \%$ of the pixels have a dark count rate lower than $8 \mathrm{kHz}$, which is in line with other works [61,62]. Figure 10 shows a typical dark count profile of the SPAD sensor array at normal operation conditions.

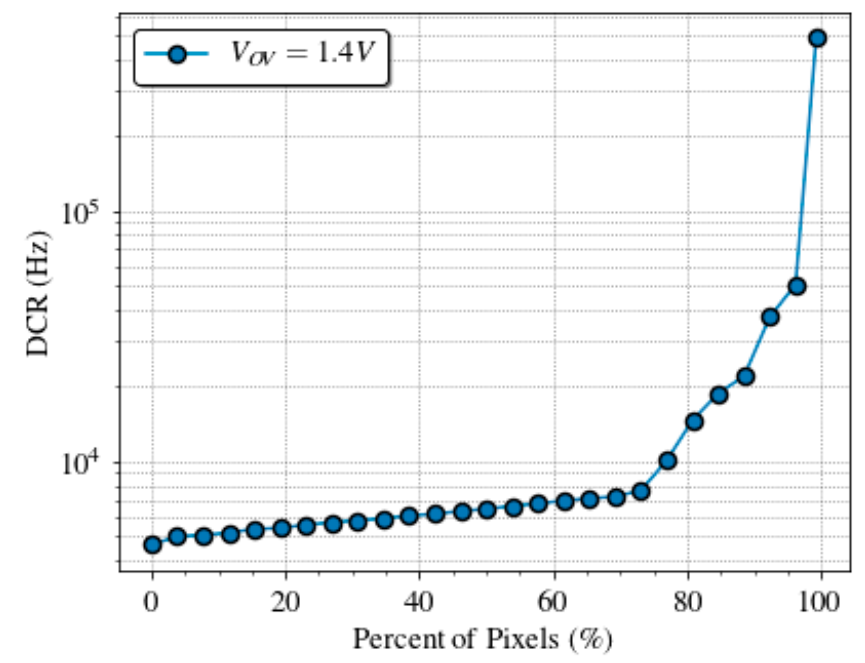

Figure 9. Dark count rate distribution measured across the SPAD array of 13 chips at $1.4 \mathrm{~V}$ of overvoltage and room temperature with a maximum relative error of $0.5 \%$.

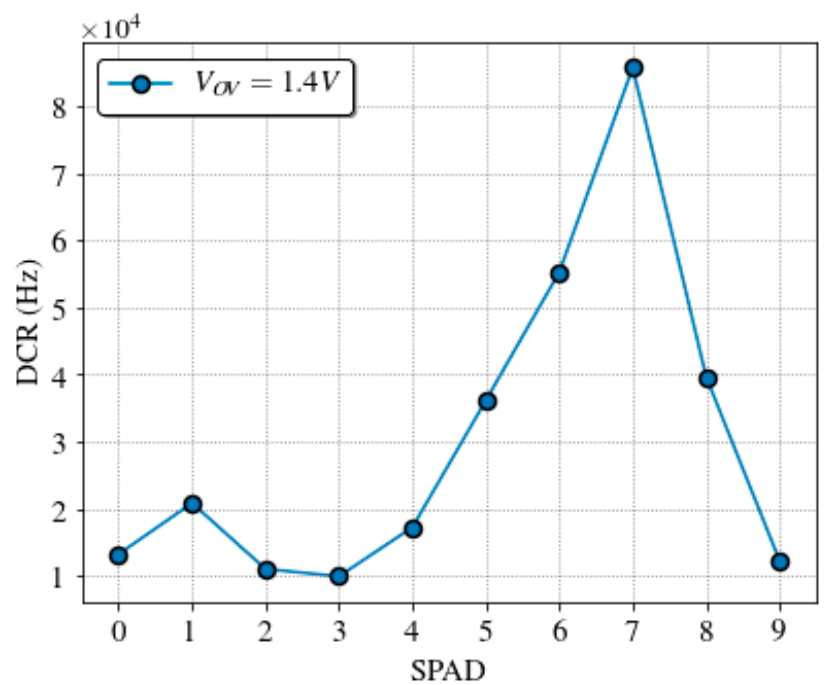

Figure 10. Dark count rate profile (with a maximum relative error of $0.5 \%$ ) of the used SPAD sensor array at $1.4 \mathrm{~V}$ of overvoltage and room temperature.

The PDP spectral response of the SPAD has been measured using an electro-optical bench composed by a white-light source, a monochromator filter, and a calibrated reference detector. Figure 11 shows the PDP of a single SPAD in a wavelength range 300-1000 nm for overvoltage of $1.4 \mathrm{~V}$ at room temperature. In good agreement, with other works such as [63]. The SPAD presents a good efficiency over the visible range with a maximum of $25 \%$ at about $480 \mathrm{~nm}$, and a $15 \%$ at the emission wavelength of the QD605, which is $605 \mathrm{~nm}$, at normal operation conditions. 


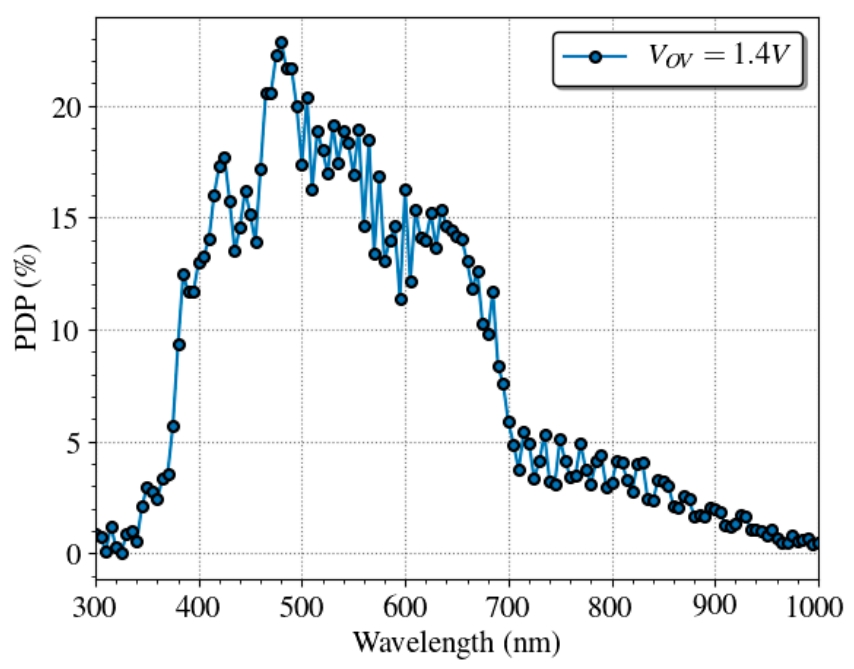

Figure 11. Spectral dependence of the PDP of a single SPAD at $1.4 \mathrm{~V}$ of overvoltage with a maximum relative error of $0.5 \%$. The PDP shows interference patterns caused by the passivation layers.

\subsection{System Performance}

Quantum dot samples, QD605 in Phosphate Buffer Saline (PBS), were prepared at concentrations of $1,1 / 2,1 / 4,1 / 8,1 / 16$, and $1 / 32 \mu \mathrm{M}$. A volume of $0.4 \mu \mathrm{L}$ of each sample was loaded into the microchannel of the microfluidic cartridge. An effective sample volume of $20 \mathrm{~nL}$ (microchannel volume illuminated by the laser spot) was excited to obtain each decay curve in less than a minute. The experiments were carried in normal operation conditions at room temperature in a dark environment, with the SPAD sensor biased at $1.4 \mathrm{~V}$ of overvoltage. The dark count rate profile for the SPAD sensor chip used is shown in Figure 10.

A first experiment was done to determine the sensitivity of the PoC-MD. To guarantee the best SNR, the microchannel was fixed on the SPAD with lower noise. The results of the fluorescence decay measurements performed are shown in Figure 12 along with a PBS measurement without quantum dot as a reference. A Savitzky-Golay filter was applied to the PBS reference presented in the figure for clarity in the representation. As expected, the fluorescence intensity decreases with fluorophore concentration. For the $1 / 32 \mu \mathrm{M}$ concentration, the decay curve is below the PBS reference, due to the combination of the quantum efficiency, the scattered emission of the QD605 and the absorption of the emitted photons by the neighbour QDs, which reduces the light reaching the active area of the SPAD. The other concentrations follow decay curves above the PBS reference one with three different behaviours. At the beginning, from 20 to $50 \mathrm{~ns}$, the decay curves present higher decay rates because of the laser pulse tail, clearly visible at the beginning of the PBS curve. From the 50 ns mark, the QD605 fluorescence becomes the predominant effect and the decay curves can be approximated to a mono-exponential decay, showing a linear behaviour in a logarithmic representation, as can be seen in the zones highlighted in orange. At last, at the end of the measuring period, the decay rate slows down as it reaches the noise level.

To extract the lifetime, we made a linear fit to the logarithmic representation of the intensity decays on the second region of each curve, setting the cut-off point of the fitted data at three times the noise level. The lifetime is then the inverse of the slope of the resulting line. Lifetimes of 32.4, 32.5, $32.6,32.7$, and $32.4 \mathrm{~ns}$ with a $500 \mathrm{ps}$ of error were obtained for the fluorophore concentrations of 1 , $1 / 2,1 / 4,1 / 8$, and $1 / 16 \mu \mathrm{M}$, respectively. These lifetime estimations are in agreement with those in the literature $[55,64]$. With this set of concentrations of QD605, the detection limit for our system is a concentration of $1 / 16 \mu \mathrm{M}$ for both lifetime and intensity. Moreover, to the best of our knowledge, the $1 / 16 \mu \mathrm{M}$ is the lowest reported concentration from which a low cost instrument with neither optical lenses nor filters has extracted the fluorescence lifetime $[8,15,26]$. 

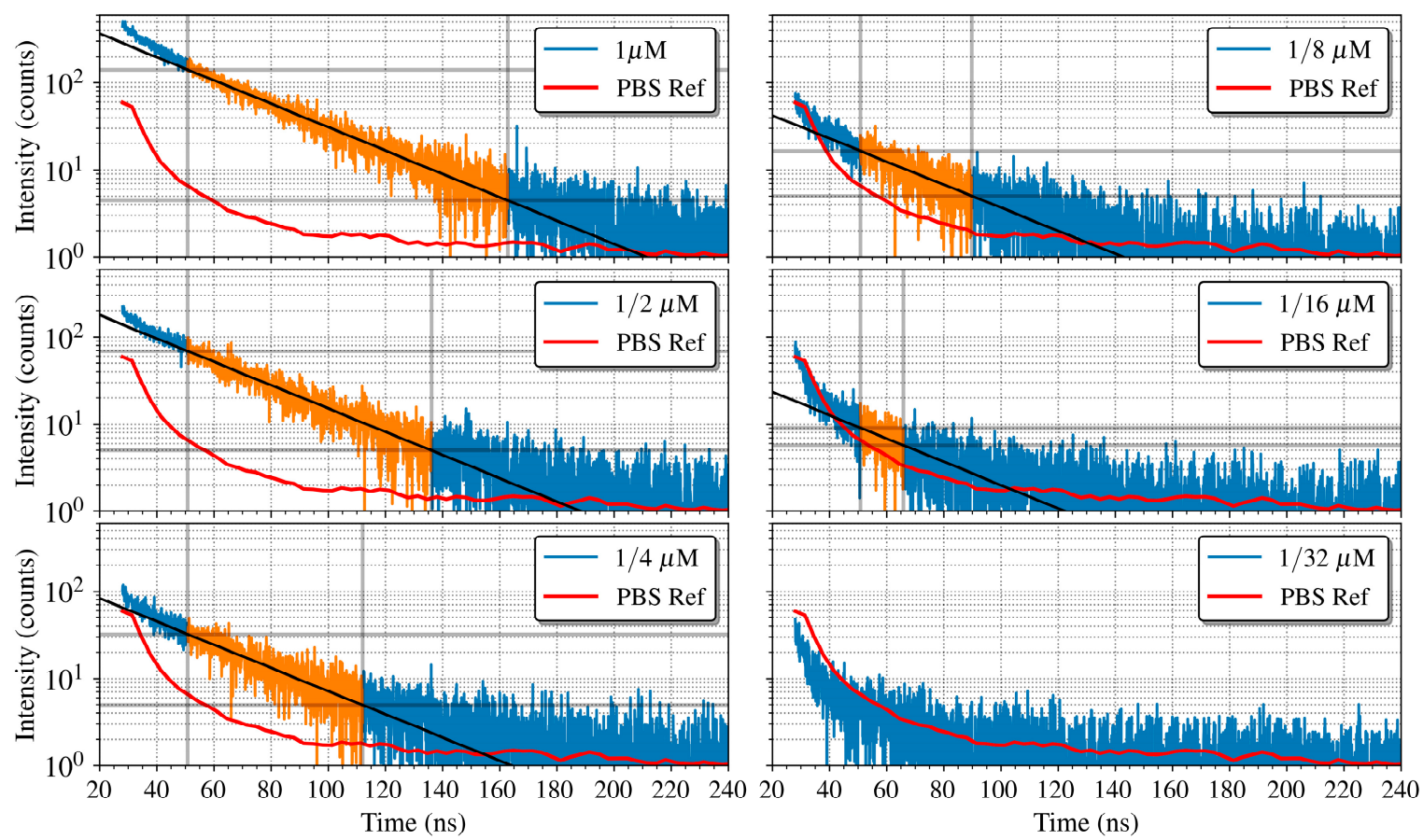

Figure 12. Fluorescence decay curves measured using the SPAD located below the microchannel for different concentrations of QD605 (with a maximum relative error of $0.5 \%$ ), together with fitting lines used to determine the lifetimes for each concentration. The adjustment lines are calculated using only the points where the predominant effect is the decay of QD605 (highlighted in orange).

A second experiment was conducted to study the possibility of using one SPAD regardless of the position of the microchannel over it, as well as checking if it is possible to perform the analysis of two or more samples simultaneously in a microfluidic cartridge with more than one micro channel, labelled with the same fluorophore. To do so, we studied how the detected signal varies with the distance between the SPAD and the microchannel for different concentrations. Taking advantage of the fact that the SPADs have a constant pitch of $50 \mu \mathrm{m}$ in the array, we placed the microchannel over the first SPAD (number 0 ) and performed the measurement of the fluorescence intensity and its decay rate for all concentrations with every SPAD on the array.

Figure 13 shows the fluorescence intensity (total accumulated counts) in the time interval when the predominant contribution is the fluorescence of the QD605 label (from 50 to $75 \mathrm{~ns}$ ), measured for each SPAD and concentration, as well as the PBS reference. As expected, the intensity of the signal decreases with the distance between the microchannel and the sensor. The PBS reference measurements present a profile similar to the DCR of Figure 10, which sets the detection limit along the SPAD sensor array. The intensity level for the $1 / 32 \mu \mathrm{M}$ sample is always below the PBS reference, as expected from the previous experiment. The $1 / 8$ and $1 / 16 \mu \mathrm{M}$ concentrations can be detected until the 6th SPAD, meaning that the system operates in optimal conditions with a distance between SPAD and sample of up to $300 \mu \mathrm{m}$. Higher concentrations can be detected even with the noisiest SPAD of the array, number seven at $350 \mu \mathrm{m}$, which has eight times the noise of the best one.

Additionally, we calculated the quantum dot lifetime as done for the previous experiment for each concentration and SPAD along the array. Figure 14 shows the extracted lifetimes for the different combinations. As expected, the lifetimes can be extracted only where the detected signal is over the PBS reference signal. The extracted lifetimes are consistent with the previous results along the whole array, with a mean value $(\mu)$ of $32.7 \mathrm{~ns}$ and a standard deviation $(\mu \pm \sigma)$ of $0.2 \mathrm{~ns}$. 


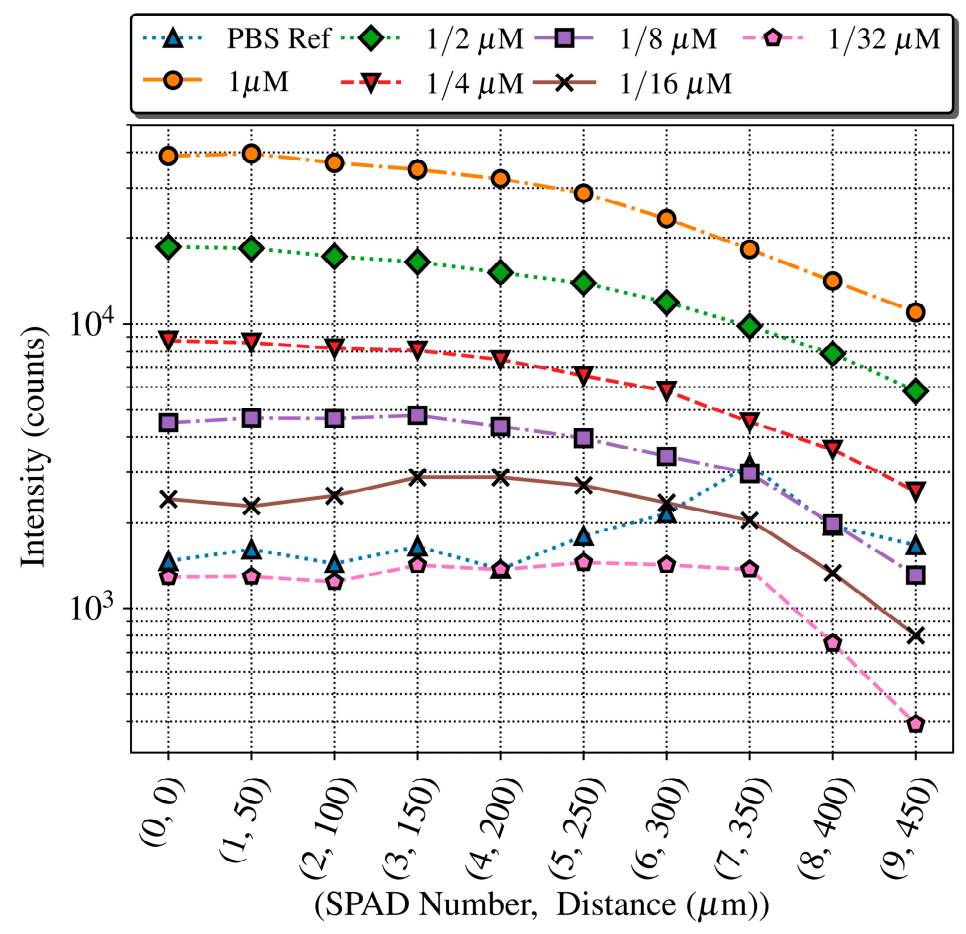

Figure 13. Fluorescence intensity measured across the SPAD array within the time slice 50-75 ns (with a maximum relative error of $0.5 \%$ ), showing how the level detected decreases with the distance.

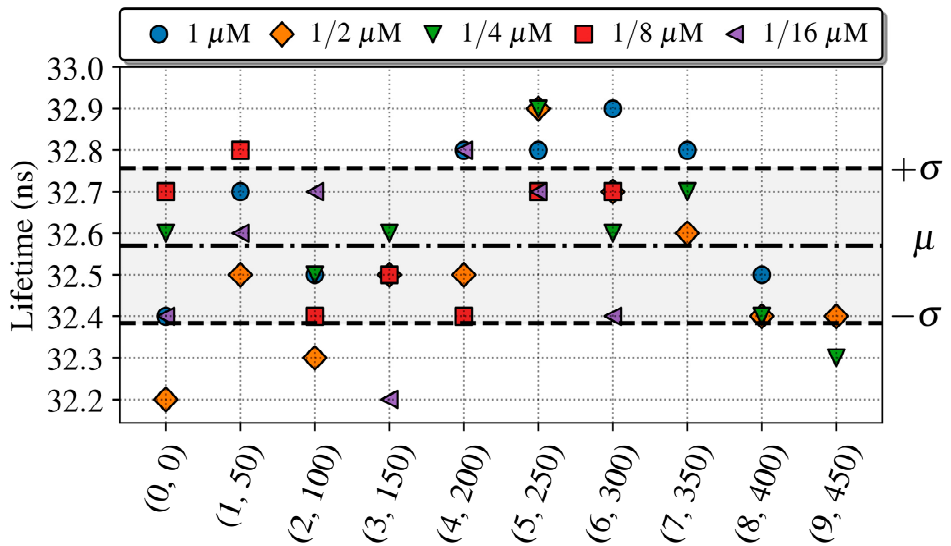

(SPAD Number, Distance $(\mu \mathrm{m})$ )

Figure 14. Fluorescent life times of QD605 extracted along the SPAD array for concentrations of 1, 1/2, $1 / 4,1 / 8$ and $1 / 16 \mu \mathrm{M}$, with the microchannel placed over the SPAD0. The lifetime estimation error is 500 ps.

In view of the results, we conclude that regardless of where the microchannel falls within the array, it will always be possible to choose among the SPADs one with the sufficient SNR to perform the intensity and lifetime measurements, even in cases in which the microchannel falls out of the array. This gives a good margin of tolerance for the manufacture of the microfluidic cartridge and the SU8 stopper.

Furthermore, the results indicate that it is not possible to analyse two or more samples simultaneously using a single microfluidic cartridge with two or more channels, since they would interfere significantly with the measurements from the others ones. One possibility to explore in order to get around this problem would be to use different fluorophores on each channel, each one decaying according to a different lifetime, and fit a multi-exponential decay on the obtained curves [7]. Such experiment requires fluorophores with long yet different lifetimes, and is out of the scope of 
the present work. An alternative to the multi-exponential decay analysis might be multiplexing the sample over time. This method consists in reusing the microchannel with different samples, cleaning it after each measurement. This presents two main drawbacks: the absorption of small molecules such as drugs and proteins on the PDMS surface, which has been identified as a major problem for molecular biology $[65,66]$, and the automation of the process, which requires the use of micro-pumps, incrementing the complexity of the setup $[27,29]$. Further investigation needs to be undertaken to deepen into this issue.

Our PoC-MD builds on the advantages of the cheap single use microfluidic cartridge to offer an elegant and useful solution. The sample can be changed without any alignment procedure, performing the measurement with all the SPADs and analysing the decay curve with best SNR. To prepare the device for industrialization, we need to bring down the size and cost for each device. To do so, we would stop using the expensive commercial development board (such as the Zedboard used in the prototype), moving the control and processing electronics into a custom integrated PCB. We also need an alternative to the PDMS used for the microfluidics, because its production volume is low, of the order of 300-1000 units per month according to Reference [67]. Other materials used to manufacture microfluidics are thermoplastics (like PMMA, COP, PS, PM, COC), but they present autofluorescence emission [68]. The best candidate is a soft ThermoPlastic Elastomer (sTPE), Flexdym, which claims to alleviate PDMS drawbacks in microfluidics (quick prototyping, absorption and substrate bonding) while keeping the advantages (softness, optical properties, biocompatibility and gas permeability) [69]. Flexdym fabrication process can be performed using a hot embossing machine or very simple press equipment, making it compatible with rapid manufacturing technology such as injection molding or roll-to-roll.

\section{Conclusions}

In this paper, we present a fluorescence lifetime spectroscopy $\mathrm{PoC}$ for molecular diagnosis that is small, low-cost and easy to assemble, by joining the advantages of a linear array of ultra-sensitive CMOS SPAD-based detectors with a custom PDMS microfluidic cartridge that works with a coarse easy alignment. Moreover, the device avoids the need of any optical filter to remove the excitation light by beginning the measurement process after it has faded below the fluorescence, but that limits the fluorophores to those with long lifetimes, such as the QD605. The SPAD, makes it possible to detect low concentrations of fluorophores thanks to its sensitivity over a wide range of wavelengths.

The results show that the system is able to build the histogram of the fluorescence decay and measure the lifetime from very small sample volumes $(20 \mathrm{~nL})$ at practical concentration levels $(62.5 \mathrm{nM})$ in a few seconds. Nevertheless, the detection limit is determined by the noise of the SPAD. Even with the noise limitation, the use of commercial components combined with an ultra-sensitive detector and a removable microfluidic cartridge makes the PoC-MD a low-cost system with great versatility, which holds large potential for applications in an analytical laboratory, clinical diagnosis, at the point-of-care, or in a resource limited environment.

The way towards industrialization of this device has been explored, involving the need to reduce size and cost. PDMS seems to be the more limiting material and a soft thermoplastic elastomer (as Flexdym) appears as the best alternative to PDMS.

Author Contributions: A.D. and J.C. conceived the device and the experiment; J.C. performed the experiments and construct the device; A.D. and O.A. design the sensors chip; J.C. and A.V. design the microfluidics; J.C. and N.F. design and implements the controller and software; J.C. analysed data and wrote the paper; A.D. is the principal investigator he supervises the research and he also participated to the final approval of the manuscript submission.

Funding: This research was funded by ACC1Ó grant number VALTEC13-1-0020-00 and The APC was funded by European Union's Horizon 2020 research and innovation program under grant agreement No 737089.

Acknowledgments: This work has been partially supported by ACC1Ó in Catalonia through the Project "Portable device for molecular diagnosis" coded VALTEC13-1-0020-00, by the European Union's Horizon 2020 research and innovation program under grant agreement No 737089. 
Conflicts of Interest: The authors declare no conflict of interest.

\section{References}

1. Marcu, L.; French, P.M.W.; Elson, D.S. Fluorescence Lifetime Spectroscopy and Imaging: Principles and Applications in Biomedical Diagnostics; CRC Press: Boca Raton, FL, USA, 2014. [CrossRef]

2. Léonard, J.; Dumas, N.; Caussé, J.; Maillot, S.; Giannakopoulou, N.; Barre, S.; Uhring, W. High-throughput time-correlated single photon counting. Lab Chip 2014, 14, 4338-4343. [CrossRef]

3. Bastiaens, P.I.H.; Squire, A. Fluorescence lifetime imaging microscopy: Spatial resolution of biochemical processes in the cell. Trends Cell Biol. 1999, 9, 48-52. [CrossRef]

4. Stöckl, M.T.; Bizzarri, R.; Subramaniam, V. Studying Membrane Properties Using Fluorescence Lifetime Imaging Microscopy (FLIM). In Fluorescent Methods to Study Biological Membranes, Springer Series on Fluorescence (Methods and Applications), 1st ed.; Mély, Y., Duportail, G., Eds.; Springer: Berlin/Heidelberg, Germany, 2013; Volume 13, pp. 215-240. [CrossRef]

5. Saxena, A.; Udgaonkar, J.B.; Krishnamoorthy, G. Protein Dynamics and Protein Folding Dynamics Revealed by Time-Resolved Fluorescence. In Fluorescence Spectroscopy in Biology, Springer Series on Fluorescence (Methods and Applications), 1st ed.; Hof, M., Hutterer, R., Fidler, V., Eds.; Springer: Berlin/Heidelberg, Germany, 2005; Volume 3, pp. 163-179. [CrossRef]

6. Marcu, L. Fluorescence Lifetime Techniques in Medical Applications. Ann. Biomed. Eng. 2012, 40, 304-331. [CrossRef] [PubMed]

7. Berezin, M.Y.; Achilefu, S. Fluorescence Lifetime Measurements and Biological Imaging. Chem. Rev. 2010, 110, 2641-2684. [CrossRef] [PubMed]

8. Salthouse, C.D.; Weissleder, R.; Mahmood, U. Development of a time domain fluorimeter for fluorescent lifetime multiplexing analysis. IEEE Trans. Biomed. Circuits Syst. 2008, 2, 204-211. [CrossRef] [PubMed]

9. Kobayashi, H.; Ogawa, M.; Alford, R.; Choyke, P.L.; Urano, Y. New strategies for fluorescent probe design in medical diagnostic imaging. Chem. Rev. 2010, 110, 2620-2640. [CrossRef]

10. Pires, L.; Nogueira, M.S.; Pratavieira, S.; Moriyama, L.T.; Kurachi, C. Time-resolved fluorescence lifetime for cutaneous melanoma detection. Biomed. Opt. Express 2014, 5, 3080-3089. [CrossRef]

11. Cosci, A.; Nogueira, M.S.; Pratavieira, S.; Takahama, A., Jr.; Souza, R.; Kurachi, C. Time-resolved fluorescence spectroscopy for clinical diagnosis of actinic cheilitis. Biomed. Opt. Express 2016, 7, 4210-4219. [CrossRef]

12. Ardeshirpour, Y.; Chernomordik, V.; Hassan, M.; Zielinski, R.; Capala, J.; Gandjbakhche, A. In Vivo Fluorescence Lifetime Imaging for Monitoring the Efficacy of the Cancer Treatment. Clin. Cancer Res. 2014, 20, 3531-3539. [CrossRef]

13. Bai, M. (Ed.) In Vivo Fluorescence Imaging Methods and Protocols, 1st ed.; Humana Press: New York, NY, USA, 2016; ISBN 978-1-4939-8119-9. [CrossRef]

14. Petryayeva, E.; Algar, W.R.; Medintz, I.L. Quantum Dots in Bioanalysis: A Review of Applications across Various Platforms for Fluorescence Spectroscopy and Imaging. Appl. Spectrosc. 2013, 67, 215-252. [CrossRef]

15. Sulkes, M.; Sulkes, Z. Measurement of luminescence decays: High performance at low cost. Am. J. Phys. 2011, 79, 1104-1111. [CrossRef]

16. Elson, D.S.; Siegel, J.; Webb, S.E.; Lévêque-Fort, S.; Lever, M.J.; French, P.M.; Lauritsen, K.; Wahl, M.; Erdmann, R. Fluorescence lifetime system for microscopy and multiwell plate imaging with a blue picosecond diode laser. Opt. Lett. 2002, 27, 1409-1411. [CrossRef] [PubMed]

17. Marcu, L.; Jo, J.A.; Fang, Q.; Papaiannou, T. Applications of time-resolved fluorescence spectroscopy to atherosclerotic cardiovascular disease and brain tumors diagnosis. In Proceedings of the Conference on Lasers and Electro-Optics, Baltimore, MD, USA, 22-27 May 2005; pp. 2227-2229. [CrossRef]

18. Nguyen, T.; Zoëga Andreasen, S.; Wolff, A.; Duong Bang, D. From Lab on a Chip to Point of Care Devices: The Role of Open Source Microcontrollers. Micromachines 2018, 9, 403. [CrossRef] [PubMed]

19. Yu, L.; Ng, S.R.; Xu, Y.; Dong, H.; Wang, Y.J.; Li, C.M. Advances of lab-on-a-chip in isolation, detection and post-processing of circulating tumour cells. Lab Chip 2013, 13, 3163-3182. [CrossRef] [PubMed]

20. Pfeiffer, S.A.; Nagl, S. Microfluidic platforms employing integrated fluorescent or luminescent chemical sensors: A review of methods, scope and applications. Methods Appl. Fluoresc. 2015, 3, 034003. [CrossRef] [PubMed] 
21. Wu, J.; Gu, M. Microfluidic sensing: State of the art fabrication and detection techniques. J. Biomed. Opt. 2011, 16, 080901. [CrossRef]

22. Yeo, L.Y.; Chang, H.C.; Chan, P.P.Y.; Friend, J.R. Microfluidic devices for bioapplications. Small 2011, 7, $12-48$. [CrossRef]

23. Norian, H.; Field, R.M.; Kymissis, I.; Shepard, K.L. An integrated CMOS quantitative-polymerasechain-reaction lab-on-chip for point-of-care diagnostics. Lab Chip 2014, 14, 4076-4084. [CrossRef]

24. Schwartz, D.E.; Charbon, E.; Shepard, K.L. A Single-Photon Avalanche Diode Array for Fluorescence Lifetime Imaging Microscopy. IEEE J. Solid-State Circuits 2008, 43, 2546-2557. [CrossRef]

25. Li, D.-U.; Walker, R.; Richardson, J.; Rae, B.; Buts, A.; Renshaw, D.; Henderson, R. FPGA implementation of a video-rate fluorescence lifetime imaging system with a $32 \times 32$ CMOS single-photon avalanche diode array. In Proceedings of the IEEE International Symposium on Circuits and Systems, Taipei, Taiwan, 24-27 May 2009; pp. 3082-3085. [CrossRef]

26. Wang, H.; Qi, Y.; Mountziaris, T.J.; Salthouse, C.D. A portable time-domain LED fluorimeter for nanosecond fluorescence lifetime measurements. Rev. Sci. Instrum. 2014, 85, 055003. [CrossRef]

27. Kwon, O.; Lee, K.; Lee, D. An automated point-of-care instrument for molecular testing. In Proceedings of the 2015 15th International Conference on Control, Automation and Systems (ICCAS), Busan, Korea, 13-16 October 2015; pp. 1275-1278. [CrossRef]

28. Yokoyama, H.; Guo, H.; Yoda, T.; Takashima, K.; Sato, K.-S.; Taniguchi, H.; Ito, H. Two-photon bioimaging with picosecond optical pulses from a semiconductor laser. Opt. Express 2006, 14, 3467-3471. [CrossRef] [PubMed]

29. Emory, J.M.; Peng, Z.; Young, B.; Hupert, M.L.; Rousselet, A.; Patterson, D.; Ellison, B.; Soper, S.A. Design and development of a field-deployable single-molecule detector (SMD) for the analysis of molecular markers. Analyst 2012, 137, 87-97. [CrossRef] [PubMed]

30. Axelrod, D. Cell-Substrate Contacts Illuminated by Total Internal Reflection Fluorescence. J. Cell Biol. 1981, 89, 141-145. [CrossRef] [PubMed]

31. Nakazato, H.; Kawaguchi, H.; Iwabuchi, A.; Hane, K. Integrated fluorescent analysis system with monolithic GaN light emitting diode on Si platform. In Proceedings of the IEEE 25th International Conference on Micro Electro Mechanical Systems (MEMS), Paris, France, 29 January-2 February 2012; pp. 842-845. [CrossRef]

32. Rae, B.R.; Yang, J.; McKendry, J.; Gong, Z.; Renshaw, D.; Girkin, J.M.; Gu, E.; Dawson, M.D.; Henderson, R.K. A Vertically Integrated CMOS Microsystem for Time-Resolved Fluorescence Analysis. IEEE Trans. Biomed. Circuits Syst. 2010, 4, 437-444. [CrossRef] [PubMed]

33. Rae, B.R.; Griffin, C.; McKendry, J.; Girkin, J.M.; Zhang, H.X.; Gu, E.; Renshaw, D.; Charbon, E.; Dawson, M.D.; Henderson, R.K. CMOS driven micro-pixel LEDs integrated with single photon avalanche diodes for time resolved fluorescence measurements. J. Phys. D Appl. Phys. 2008, 41, 094011. [CrossRef]

34. Cova, S.; Ghioni, M.; Lacaita, A.; Samori, C.; Zappa, F. Avalanche photodiodes and quenching circuits for single-photon detection. Appl. Opt. 1996, 35, 1956-1976. [CrossRef]

35. Becker, W. Advanced Time-Correlated Single Photon Counting Techniques, 1st ed.; Springer: Berlin/Heidelberg, Germany, 2005; p. 401. ISBN 978-3-540-26047-9. [CrossRef]

36. Piruska, A.; Nikcevic, I.; Lee, S.H.; Ahn, C.; Heineman, W.R.; Limbach, P.A.; Seliskar, C.J. The autofluorescence of plastic materials and chips measured under laser irradiation. Lab Chip 2005, 5, 1348-1354. [CrossRef]

37. Stoppa, D.; Mosconi, D.; Pancheri, L.; Gonzo, L. Single-Photon Avalanche Diode CMOS Sensor for Time-Resolved Fluorescence Measurements. IEEE Sens. J. 2009, 9, 1084-1090. [CrossRef]

38. Lakowicz, J.R. Principles of Fluorescence Spectroscopy, 3rd ed.; Springer Science+Business Media LLC: New York, NY, USA, 2006; pp. 15-16. ISBN 978-0387-31278-1.

39. Kapusta, P.; Wahl, M.; Erdmann, R. Advanced Photon Counting: Applications, Methods, Instrumentation, 1st ed.; Springer International Publishing: New York, NY, USA, 2015. [CrossRef]

40. Vilella, E.; Alonso, O.; Montiel, A.; Vilà, A.; Diéguez, A. A low-noise time-gated single-photon detector in a HV-CMOS technology for triggered imaging. Sens. Actuators A Phys. 2013, 201, 342-351. [CrossRef]

41. Tisa, S.; Guerrieri, F.; Zappa, F. Variable-load quenching circuit for single-photon avalanche diodes. Opt. Express 2008, 16, 2232-2244. [CrossRef]

42. Vilella, E.; Comerma, A.; Alonso, O.; Gascon, D.; Diéguez, A. Gated Geiger mode avalanche photodiode pixels with integrated readout electronics for low noise photon detection. Nucl. Instrum. Methods Phys. Res. Sect. A Accel. Spectrome. Detect. Assoc. Equip. 2012, 695, 218-221. [CrossRef] 
43. Malass, I.; Uhring, W.; Le Normand, J.P.; Dumas, N.; Dadouche, F. Evaluation of size influence on performance figures of a single photon avalanche diode fabricated in a $180 \mathrm{~nm}$ standard CMOS technology. Analog Integr. Circuits Signal Process. 2016, 89, 69-76. [CrossRef]

44. MicroChem Corporation. SU-8 50-100 Datasheet. Available online: http://www.microchem.com/pdf/SU8_ 50-100.pdf (accessed on 15 September 2017).

45. Conradie, E.H.; Moore, D.F. SU-8 thick photoresist processing as a functional material for MEMS applications. J. Micromech. Microeng. 2002, 12, 368-374. [CrossRef]

46. Duffy, D.C.; McDonald, J.C.; Schueller, O.J.A.; Whitesides, G.M. Rapid prototyping of microfluidic systems in poly(dimethylsiloxane). Anal. Chem. 1998, 70, 4974-4984. [CrossRef]

47. Elveflow. Pdms Softlithography. Available online: http://www.elveflow.com/microfluidic-tutorials/softlithography-reviews-and-tutorials / introduction-in-soft-lithography/pdms-softlithography-replication/ (accessed on 15 September 2017).

48. Elveflow. SU-8 Mold Lithography. Available online: http://www.elveflow.com/microfluidic-tutorials/softlithography-reviews-and-tutorials / introduction-in-soft-lithography/su-8-mold-lithography/ (accessed on 15 September 2017).

49. Sushanta, M.K.; Chakraborty, S. Microfluidics and Nanofluidics Handbook: Fabrication, Implementation, and Applications, 1st ed.; CRC Press: Boca Raton, FL, USA, 2012; pp. 231-261. ISBN 9781439816738.

50. Araki, T.; Misawa, H. Light emitting diode-based nanosecond ultraviolet light source for fluorescence lifetime measurements. Rev. Sci. Instrum. 1995, 66, 5469-5472. [CrossRef]

51. Franzen, D.L.; Day, G.W. LED source for determining optical detector time response at $1.06 \mu \mathrm{m}$. Rev. Sci. Instrum. 1979, 50, 1029-1031. [CrossRef] [PubMed]

52. Vanderwall, J.; Hattery, W.V.; Sztankay, Z.G. Subnanosecond Rise Time Pulses from Injection Lasers. IEEE J. Quantum Electron. 1974, 10, 570-572. [CrossRef]

53. Chadderton, N.; Is, W.; Avalanche, A. (AN-8) The ZTX415 Avalanche Mode Transistor. Zetex Application Note. 1996. Available online: https://www.digchip.com/application-notes/3/33511.php (accessed on 28 July 2018).

54. Vainshtein, S.N.; Yuferev, V.S.; Kostamovaara, J.T. Properties of the transient of avalanche transistor switching at extreme current densities. IEEE Trans. Electron Devices 2002, 49, 142-149. [CrossRef]

55. Franch, N.; Alonso, O.; Canals, J.; Vilà, A.; Dieguez, A. A low cost fluorescence lifetime measurement system based on SPAD detectors and FPGA. J. Instrum. 2017, 12. [CrossRef]

56. Li, D.-U.; Rae, B.R.; Renshaw, D.; Henderson, R.; Bonnist, E. On-Chip fluorescence lifetime extraction using synchronous gating scheme theoretical error analysis and practical implementation. In Proceedings of the First International Conference on Bio-inspired Systems and Signal Processing, Funchal, Madeira, Portugal, 28-31 January 2008; pp. 171-176. [CrossRef]

57. Niclass, C.; Favi, C.; Kluter, T.; Gersbach, M.; Charbon, E. A 128x128 Single-Photon Image Sensor with Column-Level 10-Bit Time-to-Digital Converter Array. IEEE J. Solid-State Circuits 2008, 43, 2977-2989. [CrossRef]

58. Veerappan, C.; Richardson, J.; Walker, R.; Li, D.-U.; Fishburn, M.W.; Maruyama, Y.; Stoppa, D.; Borghetti, F.; Gersbach, M.; Henderson, R.K.; et al. A 160x128 single-photon image sensor with on-pixel 55ps 10b time-to-digital converter. In Proceedings of the International Solid-State Circuits Conference, San Francisco, CA, USA, 20-24 February 2011. [CrossRef]

59. Gersbach, M.; Maruyama, Y.; Trimananda, R.; Fishburn, M.W.; Stoppa, D.; Richardson, J.; Walker, R.; Henderson, R.; Charbon, E. A time-resolved, low-noise single-photon image sensor fabricated in deep-submicron CMOS technology. IEEE J. Solid-State Circuits 2012, 47, 1394-1407. [CrossRef]

60. Charbon, E.; Fishburn, M.; Walker, R.; Henderson, R.K.; Niclass, C. SPAD-Based Sensors. In TOF Range-Imaging Cameras, 1st ed.; Remondino, F., Stoppa, D., Eds.; Springer: Berlin/Heidelberg, Germany, 2013; pp. 11-38. [CrossRef]

61. Accarino, C.; Al-Rawhani, M.; Shah, Y.D.; Maneuski, D.; Mitra, S.; Buttar, C.; Cumming, D.R.S. Low Noise and High Photodetection Probability SPAD in $180 \mathrm{~nm}$ Standard CMOS Technology. In Proceedings of the ISCAS 2018, Florence, Italy, 27-30 May 2018. [CrossRef]

62. Faramarzpour, N.; Deen, M.J.; Shirani, S.; Fang, Q. Fully integrated single photon avalanche diode detector in standard CMOS 0.18- $\mu \mathrm{m}$ technology. IEEE Trans. Electron. Devices 2008, 55, 760-767. [CrossRef] 
63. Mandai, S.; Fishburn, M.W.; Maruyama, Y.; Charbon, E. A wide spectral range single-photon avalanche diode fabricated in an advanced $180 \mathrm{~nm}$ CMOS technology. Opt. Express 2012, 20, 5849-5857. [CrossRef] [PubMed]

64. Gaigalas, A.K.; Derose, P.; Wang, L.; Zhang, Y.-Z. Optical Properties of CdSe/ZnS Nanocrystals. J. Res. Natl. Inst. Stand. Technol. 2014, 119, 610-628. [CrossRef]

65. Van Meer, B.J.; De Vries, H.; Firth, K.S.A.; Van Weerd, J.; Tertoolen, L.G.J.; Karperien, H.B.J.; Jonkheijm, P.; Denning, C.; IJzerman, A.P.; Mummerya, C.L. Small molecule absorption by PDMS in the context of drug response bioassays. Biochem. Biophys. Res. Commun. 2017, 482, 323-328. [CrossRef] [PubMed]

66. Gokaltun, A.; Yarmush, M.L.; Asatekin, A.; Usta, O.B. Recent advances in nonbiofouling PDMS surface modification strategies applicable to microfluidic technology. Technology 2017, 5, 1-12. [CrossRef]

67. Chia-Wen, T. Polymer Microfluidics: Simple, Low-Cost Fabrication Process Bridging Academic Lab Research to Commercialized Production. Micromachines 2016, 7, 225. [CrossRef]

68. Young, E.W.K.; Berthier, E.; Beebe, D.J. Assessment of Enhanced Autofluorescence and Impact on Cell Microscopy for Microfabricated Thermoplastic Devices. Anal. Chem. 2013, 85, 44-49. [CrossRef] [PubMed]

69. Lachaux, J.; Alcaine, C.; Gómez-Escoda, B.; Perrault, C.M.; Duplan, D.O.; Wu, P.Y.J.; Ochoa, I.; Fernandez, L.; Mercier, O.; Coudreuse, D.; et al. Thermoplastic elastomer with advanced hydrophilization and bonding performances for rapid (30 s) and easy molding of microfluidic devices. Lab Chip 2017, 17, 2581-2594. [CrossRef]

(C) 2019 by the authors. Licensee MDPI, Basel, Switzerland. This article is an open access article distributed under the terms and conditions of the Creative Commons Attribution (CC BY) license (http:/ / creativecommons.org/licenses/by/4.0/). 